Please do not remove this page

RMIT

UNIVERSITY

\title{
WOM source characteristics and message quality: the receiver perspective
}

Le, Dinh Minh Tri; Dobele, Angela; Robinson, Linda

https://researchrepository.rmit.edu.au/esploro/outputs/9921859001401341/filesAndLinks?institution=61RMIT_INST\&index=null

Le, D. M. T., Dobele, A., \& Robinson, L. (2018). WOM source characteristics and message quality: the receiver perspective. Marketing Intelligence and Planning, 36(4), 1-17.

https://doi.org/10.1108/MIP-10-2017-0249

Document Version: Accepted Manuscript

Published Version: https://doi.org/10.1108/MIP-10-2017-0249

Repository homepage: https://researchrepository.rmit.edu.au

(c) Emerald Publishing Limited

Downloaded On 2023/04/26 19:44:22 +1000

Please do not remove this page 
Thank you for downloading this document from the RMIT Research Repository.

The RMIT Research Repository is an open access database showcasing the research outputs of RMIT University researchers.

RMIT Research Repository: http://researchbank.rmit.edu.au/

\section{Citation:}

Le, D, Dobele, A and Robinson, L 2018, 'WOM source characteristics and message quality: the receiver perspective', Marketing Intelligence and Planning, vol. 36, no. 4, pp. 440-454.

See this record in the RMIT Research Repository at:

https://researchbank.rmit.edu.au/view/rmit:47361

Version: Accepted Manuscript

\section{Copyright Statement:}

This accepted manuscript has been deposited to the RMIT Research Repository under a Creative Commons Attribution Non-commercial International Licence 4.0 (CC BY-NC 4.0). Any reuse is allowed in accordance with the terms outlined by this licence. To reuse the AAM for commercial purposes, permission should be sought by contacting permissions@emeraldinsight.com.

\section{Link to Published Version:}

https://dx.doi.org/10.1108/MIP-10-2017-0249 


\section{WOM source characteristics and message quality: The receiver perspective}

\begin{tabular}{|r|l|}
\hline Journal: & Marketing Intelligence and Planning \\
\hline Manuscript ID & MIP-10-2017-0249.R2 \\
\hline Manuscript Type: & Original Article \\
\hline Keywords: & $\begin{array}{l}\text { WOM influence, opinion leadership, trustworthiness, expertise, homophily, } \\
\text { message quality }\end{array}$ \\
\hline Abstract: & \\
\hline \multicolumn{2}{|c}{} \\
\hline
\end{tabular}

SCHOLARONE ${ }^{\text {m }}$

Manuscripts 


\title{
WOM source characteristics and message quality: The receiver perspective
}

\begin{abstract}
Purpose: Word-of-mouth (WOM) literature has identified the roles of source and message in WOM influence, but the relationship between them is yet to be investigated. This paper explores this relationship by examining the mediation of message on the impact of perceived source characteristics from the perspective of the receiver. Also considered are the mutual relationships between source characteristics and message quality.

Design/methodology/approach: A quantitative survey of prospective students was conducted to empirically examine the proposed conceptual model. A sample of 509 respondents was analysed using structural equation modelling.

Findings: The findings suggest the significant impact of expertise, trustworthiness, homophily and opinion leadership of the WOM source on the judgement of message quality and the indirect effects on WOM influence mediated by the message quality. The results also indicate the moderating effects of receiver involvement and the valence of the message on the impact of message quality.

Practical implications: The findings of this paper can inform the strategic development of WOM marketing. A deeper understanding of source characteristics and the role of the message may enable marketing practitioners to better target appropriate influencers for seeding programs that stimulate WOM communication about their brands or products.

Originality/value: This study examines how the receiver's evaluations of message content mediate the relationship between source characteristics and WOM influence. Source and message are two elements of communication which are processed when people receive information. However, nascent research examines their effects on each other. This research contributes to our understanding of this relationship through an empirical examination of the direct effects of primary source characteristics on perceived message quality.
\end{abstract}

Keywords: opinion leadership, trustworthiness, expertise, homophily, message quality, WOM influence

Paper type: Research paper 


\section{Introduction}

Word-of-mouth (WOM) communication is an influential information source during the purchase decision-making process (Bansal and Voyer, 2000). Receiving advice from a friend, seeing a complaint on social media, or reading a review on a website could affect a prospective consumer's attitude towards a product (problem recognition and information search stages) and the purchase decision. When people receive WOM messages, they process the source characteristics and the quality of message content. These two elements have been shown to individually influence both attitude and WOM acceptance (Mahapatra and Mishra, 2017).

However, the relationship between the perceived source characteristics and the perceived message quality has been largely overlooked. That is, source and message are commonly examined as two unrelated constructs in the WOM process. This study seeks to address this void by examining message quality as a mediator of the relationship between source characteristics and WOM outcomes. For example, the information provided by people deemed to be experts may be perceived as especially content-relevant, more convincing and reliable, thus, in turn, enhancing the WOM influence. The lack of knowledge regarding this mediation presents a limitation to the WOM literature, as the receivers' judgement of WOM message content may depend on the source of the message, especially with information regarding attributes consumers are unable to process. In practice, selecting a suitable source to deliver a relevant message and improve the perceived quality of message are key factors of successful WOM marketing campaigns. Therefore, it is important for marketers to understand the relationship between source characteristics and message quality, and how message quality mediates the effects of source characteristics.

How consumers process received WOM messages is demonstrated by the Elaboration Likelihood Model (ELM), which posits source and message as the two main routes of information processing, defined as central and peripheral (Cacioppo and Petty, 1984). Aligning this model with historical communication theories, WOM research has investigated source and message, as the two main constructs of the WOM process and antecedents of WOM influence (e.g. Cheung and Thadani, 2012; Mahapatra and Mishra, 2017; Sweeney et al., 2008). As the theoretical support for the propositions of this study, ELM theory also supports the mediation effect between source and message, as the attitude shift occurred from 
peripheral route (source evaluation) leads to central processing (message evaluation) that then shapes attitude change (Petty and Cacioppo, 1986).

To examine the mediating effects of message quality on source characteristics and WOM influence, this study focusses on the four most frequently mentioned source characteristics examined in the domain of WOM research: source expertise, trustworthiness, opinion leadership and homophily (Ballantine and Yeung, 2015; Chu and Kim, 2011; Gilly et al., 1998; Martin and Lueg, 2013; Reichelt et al., 2014; Wangenheim and Bayón, 2004). This study extends knowledge in this area by considering, for the first time, if each of these perceived characteristics impacts the evaluation of message quality and the indirect effects on WOM influence.

Such focus is warranted as a deeper understanding of the receiver perspective would benefit practitioners in terms of understanding how WOM information is evaluated and affects and influences on behaviour (Martin and Lueg, 2013). Thus, the findings will assist marketing practitioners to select a relevant source for their WOM marketing campaigns by identifying the opinion leaders, experts, trustworthy sources in each context. Further, while message quality is known to influence WOM effectiveness (Mazzarol et al., 2007), whether the valence of the message content (negative or positive WOM content) and the involvement on the purchase task shape its effect are unknown. Thus, the moderating effects of involvement and valence on the effect of message quality are also explored.

\section{Theoretical foundations}

Given the fundamental nature of WOM as the passing on of communication and the multiplechannel options afforded by electronic WOM (eWOM), the most appropriate definition of WOM to progress understanding is one that incorporates both traditional and electronic characteristics and functionality. Thus, based on Westbrook (1987) original definition, Berger (2014, p. 261) defined WOM as "informal communications directed at other consumers about the ownership, usage or characteristics of particular goods and services or their sellers; and it includes literal WOM, or face-to-face discussions, as well as 'word-of-mouse', or online mentions and reviews".

WOM is commonly considered from one of two main perspectives: the source or the receiver. Significantly more attention has been paid to the source perspective through 
investigations into the motivations and behaviour of WOM sources and transmission (e.g. Berger, 2014; Hennig-Thurau et al., 2004; Jalilvand et al., 2017) than to the receiver perspective (Sweeney et al., 2008). While a WOM message will not consistently lead to action, such as purchase or transmission, the influence of WOM on the receivers is affected by the factors of information processing (Martin and Lueg, 2013). Thus, further research is needed to examine WOM from the receiver perspective to achieve a deeper understanding these factors.

Of the frameworks which conceptualise the factors influencing WOM effectiveness and adoption from the receiver viewpoint, the source and message are consistently proposed as primary factors (e.g. Cheung and Thadani, 2012; Sweeney et al., 2008). The ELM suggests that receivers will evaluate the source and content of a message when processing information. This evaluation is considered in both peripheral and central routes of information processing (Cheung et al., 2009; Petty et al., 1983) and ELM theory differentiates between the two routes by considering the depth of cognitive information processing that message evaluation undergoes (Petty and Cacioppo, 1986). When receivers have high motivation and ability to process information, elaboration likelihood is high, and they tend to evaluate the message content through the central route. When receivers have both low motivation and ability to process the information, elaboration likelihood is low and they are likely to evaluate the peripheral cues or source-related factors.

Situational and individual factors have been suggested as determinants of motivation and ability. Situational factors include distraction or repetition and individual factors include knowledge or relevance (Kang and Herr, 2006). In such conditions when low elaboration likelihood occurs, the perception towards a source has a greater influence on persuasion (Bordia et al., 2005). Positive source perception would shift the peripheral attitude and lead the information receiver back to the central cognitive processing route (Petty and Cacioppo, 1986), which would then drive the attitude change of WOM receivers.

Therefore, in conditions when WOM receivers are distracted, or lack knowledge about the information received, WOM sources shape the evaluation of the message content. Moreover, in real conditions, the central and peripheral routes are not discrete, since the former, requiring minimal cognitive resources, can be a precursor to the latter (Kang and Herr, 2006). Thus, information processing is complex, and perceptions towards source and message are 
interdependent. ELM theory provides a theoretical foundation for the mediating effects and relationships of message and source variables. The conceptual model and hypothesis development discuss these effects in more detail.

\section{Conceptual model and hypothesis development}

Message quality and WOM influence

WOM influence refers to the change in attitude and/or purchase intention of consumers as an outcome of information exchange during WOM (Gilly et al., 1998). WOM influence has been widely used as the main construct to measure the consequence of WOM communication from the receiver perspective (e.g. Bansal and Voyer, 2000; Gilly et al., 1998; Voyer and Ranaweera, 2015).

Characteristics of message are one of the principles of WOM research (Allsop et al., 2007). Mazzarol et al. (2007) categorised message characteristics into the richness of the message and strength of advocacy. The richness of the message includes "content aspects, such as the language used and the degree of storytelling or depth of information involved in the message" while the strength of advocacy refer to "the power of the way the message is delivered" (Sweeney et al., 2012, p. 242). Within the scope of this study, the message quality refers to the richness of the message, as it is consistent with the term defined in ELM theory. The delivery of the message is not included in this construct because according to ELM theory, it is considered as a peripheral cue. Message quality is a key factor in the central process (Petty and Cacioppo, 1986), which is related to the content delivered, including cognitive value and the richness of argument. Therefore, a WOM message which delivers rich content would have a stronger impact on WOM influence. Hence:

\section{H1: Perceived WOM message quality is positively related to WOM influence}

\section{The effects of source characteristics on message quality}

The conceptual work of Sweeney et al. (2008) on the factors influencing WOM effectiveness suggested five source factors such as credibility, trustworthiness, expertise, homophily (tie strength) and opinion leadership. However, this study excludes source credibility from our model in line with the long-held argument that credibility is a major factor of other subdimensions including trustworthiness and expertise (e.g. Ohanian, 1990). Consequently, expertise, trustworthiness, opinion leadership and homophily are examined in this study. Previous research into source characteristics also acknowledges the importance of these four 
characteristics as the antecedents of WOM positive outcomes (e.g. Ballantine and Yeung, 2015; Martin and Lueg, 2013; Reichelt et al., 2014; Wangenheim and Bayón, 2004). However, there is no research that examines the relationships of these characteristics with WOM message quality.

Source expertise refers to the extent to which the source is perceived as having sufficient capability to provide correct information such that the seeker has no motivation to crosscheck the receiving messages due to a high level of persuasion (e.g. Bansal and Voyer, 2000). When a source has a specialised occupation or trained skills they are more likely to be considered of higher expertise (Martin and Lueg, 2013). Because of the unique position of these experts, WOM seekers tend to search for such experts and believe their recommendations (Gilly et al., 1998; Wangenheim and Bayón, 2004).

Expertise has been reported to have both a 'strong impact' (Wangenheim and Bayón, 2004) and 'no impact' (Martin and Lueg, 2013) on WOM influence. The rationale for the 'no impact' finding was the presence of the construct WOM source experience which is related to opinion leadership. This meant that WOM receivers placed greater weight on experience rather than general knowledge (Martin and Lueg, 2013). This present study considers the direct impact of source characteristics, not on WOM influence but message quality, and proposes that when consumers receive information from an expert source, they will consider the message content to be of higher quality.

H2: Perceived WOM source expertise is positively related to perceived WOM message quality

The trustworthiness of a source has been linked with the expertise to measure the credibility of communication (Hovland and Weiss, 1951; Pornpitakpan, 2004; Reichelt et al., 2014). Such a source can be more persuasive because others believe that they provide and pass on trusted information (Martin and Lueg, 2013). Compared to expertise and similarity, Reichelt et al. (2014) found that trustworthiness is the most important source characteristic, with impact on both the utilitarian and social functions of WOM. The trustworthiness of sources has been become increasingly important in eWOM because of the anonymity of message sources (Brown et al., 2007). Thus, similar to source expertise, the effects of trustworthiness on message quality are hypothesised as: 

message quality

Homophily, or similarity, refers to the degree to which the source and the receiver are perceived as having similar attributes (e.g. demographics, lifestyle, preferences, and values) (Gilly et al., 1998; Wangenheim and Bayón, 2004). Because of these similarities, WOM seekers are more likely to talk to homophilous sources. Initial works in this field support the significant influence of homophily and the tie between source and receiver (Gilly et al., 1998). However, the impact of homophily on WOM effectiveness is relatively inconsistent. Further research on determinants of WOM engagement suggests homophily is negatively associated with opinion seeking and passing behaviours and is not associated with opinion giving behaviour (Chu and Kim, 2011). The similarity between source and receiver has a positive relationship with social function but has a negative relationship with utilitarian function (Reichelt et al., 2014). Therefore, H4 is suggested as follows:

H4: Perceived WOM source homophily is negatively related to perceived WOM message quality

Opinion leadership is the most frequently mentioned characteristic in the extant literature, however, while opinion leaders are thought to share some similarities, opinion leadership and source expertise are identified as different source types (Sweeney et al., 2008). Gilly et al. (1998) found that the expertise of the source has a significant relationship with opinion leadership. While expertise refers to the positive personality attributes of the WOM source, opinion leadership is related more to source ability, motivation and will to spread WOM messages (Gilly et al., 1998). The information from influential opinion leaders would be perceived as more reliable and better quality because the receivers could not evaluate the purchase information given their lack of experience. Hence:

H5: Perceived WOM source opinion leadership is positively related to perceived WOM message quality

\section{Mediating roles of message quality}

The ELM and information processing theories suggest that both source and message affect the persuasion of information. Following the peripheral route, the peripheral attitude shift influences the central cognitive processing and attitude change in that sequence. In actual communication, when people receive information from a credible source, whether they are 
influenced solely by the source of the message or they also evaluate the message itself is unknown. That is, if there are significant mediating effects of the message marketers should also pay attention to content seeding alongside source selection. In the mass communication context, Slater and Rouner (1996) suggest that message quality mediates the relationship between initial source credibility assessment and the second assessment, as well as mediates the relationship between initial source credibility assessment and belief change. However, within WOM context, no prior research confirmed the mediation of message quality. Given the hypothesised effects of each source characteristic on message quality, and of message quality on WOM influence (Figure 1), each source characteristics is expected to have indirect effects on WOM influence mediated by message quality. Hence:

H6: Perceived WOM message quality mediates the relationship between perceived WOM source expertise and WOM influence

H7: Perceived WOM message quality mediates the relationship between perceived WOM source trustworthiness and WOM influence

H8: Perceived WOM message quality mediates the relationship between perceived WOM source homophily and WOM influence

H9: Perceived WOM message quality mediates the relationship between perceived WOM source opinion leadership and WOM influence

\section{Moderating roles of task involvement and valence}

In investigating the mediating role of message quality on WOM influence, the processing of the message by the receiver and message characteristics must also be represented. In this respect, the involvement of the receiver in message processing and the valance of the message are considered in this study as moderating the influence of message quality on WOM influence. Task involvement is examined in this study and is defined as the motivation of the receiver to be engaged in the decision-making process (Park and Lee, 2009; Sweeney et al., 2008). Involvement can be seen as the motivation to process information (Voyer and Ranaweera, 2015), which would affect the central process in ELM. Thus, WOM receivers who are highly involved in the purchase task would expend greater efforts in evaluating WOM communication factors. The moderation effect of such involvement is hypothesised as:

H10: Task involvement moderates the positive effect of perceived WOM message quality on WOM influence 


\section{Method}

\section{Sample and data collection}

Higher education was selected as an appropriate context for this study because consumers in this industry are highly involved in the decision-making process and use WOM as the main source of information (Patti and Chen, 2009). This industry can be classified as a credence service as its quality and attributes are difficult to evaluate even after purchase and consumption (Patti and Chen, 2009). The decision-making process is lengthy and prospective students receive various kinds of WOM information sources through multiple channels of communication.

Consistent with previous studies investigating source characteristics and message quality, we empirically examine the conceptual model using cross-sectional data obtained via a quantitative survey. The self-administrated survey was distributed to final-year students at three public high schools located in Ho Chi Minh City, Vietnam, who were considering applying for admission to at least one university. The three participating high schools were selected by the Department of Education and Training in Ho Chi Minh City. The chosen schools were among the largest in the city and their principals were willing to facilitate the research. Participation in the research by the students was completely voluntary, and thus constitutes a non-probability convenience sampling method. The questionnaires were returned with a total of 509 respondents used for data analysis, equating to a 35.73 per cent 
response rate across the three schools. The numbers of responses from each participating school are 205, 127 and 177. There were 316 female (62.1\%) and 193 male $(37.9 \%)$ respondents. Almost half of the respondents $(298,58.5 \%)$ had at least one sibling currently attending university or had completed a university degree.

\section{Measures and pretest}

The dependant construct WOM influence was measured by three items adopted from Bansal and Voyer (2000). The expertise of source and trustworthiness were measured using the scales of Ohanian (1990), and the opinion leadership scale was adapted from Childers (1986) to suit the context. To ascertain homophily the four-item measure adapted from Sweeney et al. (2014) was used. Message quality was measured by an eight-item scale developed by Sweeney et al. (2012) and task involvement was adapted from the involvement index of Zaichkowsky (1985). Valence was considered in terms of the information or advice received on a negative/positive single-item scale. Consistent with the established scales they were adopted from, all scales were seven-point Likert scales $(1=$ totally disagree, $7=$ totally agree), with the exception of the valence item where the Likert scale was presented as $1=$ extremely negative, $7=$ extremely positive.

In the opening of the questionnaire, screening questions ensured that only final-year high school students who were intending on applying for admission to at least one university completed the questionnaire. Further, a definition of WOM was presented to respondents, with relevant examples, to ensure that respondents understood the concept and answered questions about their WOM experiences from the same perspective. The remainder of the survey was structured following the three main themes of this research: the influence of WOM, evaluation of the source characteristics, and evaluation of the message itself. The survey concluded with a final section collecting demographic information.

The questionnaire was pretested with five Vietnamese academics, who confirmed the translation and checked for validity and readability, and five Vietnamese final-year high school students who checked for readability and ease of completion. Reliability (Cronbach's alpha values) and validity tests (convergent and discriminant validity) were performed to validate the measurement scale before the main stage of analysis. The measurement model was tested by EFA and CFA techniques, and all model-fit indices were satisfied the threshold values. 


\section{Data analysis and results}

In the first stage of measurement validation, principal component factor analysis indicates that the eigenvalues of all factors are greater than one. All factor loadings are high, and there are no significant cross-loadings with the Varimax rotation method. Before conducting the path analyses to test the hypotheses, a confirmatory factor analysis (CFA) using AMOS 22 was performed to analyse the reliability and validity of constructs measured by multi-item scales.

Maximum likelihood (ML) estimation was employed to estimate the parameters and the overall fit index of the measurement model. The measurement model consisted of expertise, trustworthiness, homophily, opinion leadership, message quality and WOM influence. The overall fit indices of the measurement model, as reported in Table 1, indicating a good model fit (Fornell and Larcker, 1981; Hair et al., 2006; MacKenzie et al., 2011), and all of the factors satisfied the conditions for reliability and validity (Hair et al., 2006).

\section{- INSERT TABLE 1 ABOUT HERE -}

Table 2 shows the results of relationships of constructs using structural equation modelling (SEM). Among the five direct hypothesised relationships, the SEM results support four of the direct relationships tested. Firstly, Message Quality is found to be strongly related to WOM Influence $(\beta=.67, p<.01)$, supporting $H 1$. Next, the relationships between the source characteristics and Message Quality were examined. A positive relationship between Source Expertise and Message Quality $(\beta=.19, \mathrm{p}<.01)$ in support of H2. Trustworthiness is also shown to have a positive significant impact on Message Quality $(\beta=.31, p<.01)$, thus H3 is also supported. Although a significant positive path was found between Homophily and Message Quality $(\beta=.07, \mathrm{p}<.05)$, the relationship is weak and conflicts with the hypothesis proposing a negative relationship. Hence, H4 is not supported. The strongest path is the relationship between Opinion Leadership and Message Quality $(\beta=.44, p<.01)$, confirming the hypothesis H5.

\section{- INSERT TABLE 2 ABOUT HERE -}


Table 2 also shows the standardised coefficients and p-value of effects of interactions on WOM Influence. The interaction of Involvement and Message Quality is found to be significant $(\beta=.09, \mathrm{p}<.01)$, so that the moderation of Involvement $(\mathrm{H} 10)$ is fully supported. This finding suggests that as the task involvement of consumers increases, the positive relationship between Message Quality and WOM Influence is strengthened (Figure 2). Next, the moderating effect of Valence is also significant $(\beta=.07, p<.05)$, supporting the hypothesis H11. Similarly, if messages deliver positive content rather than negative content, the positive relationship between Message Quality and WOM Influence is strengthened (Figure 3).

\section{- INSERT FIGURE 2 ABOUT HERE -}

\section{- INSERT FIGURE 3 ABOUT HERE -}

The mediating role of Message Quality was assessed using the bootstrapping method developed by Preacher and Hayes (2008) and implemented through the PROCESS macro offered by Hayes (2013). For the mediating effects, Table 3 shows the results of the mediation analysis with a bootstrap sample of 5,000 cases at a 95 per cent confidential interval (CI). Mediation was assessed by the indirect effect and CI values, indicated by the limits: lower level CI (LLCI) and upper level CI (ULCI). If the CI contained the value zero, it cannot be concluded that a mediation effect exists; if the CI does not contain value zero, the mediation effect can be confirmed (Hayes, 2013). All paths reflect the bootstrap CI limits not containing the value zero. That is, there is a significant indirect effect of Expertise on WOM Influence through the mediating variable Message Quality (.32, CI[.26,.38]), supporting H6. Similarly, there are significant indirect effects of Trustworthiness, Homophily and Opinion Leadership on WOM Influence through Message Quality (.36, CI[.30,.42]), (.15, CI[.11,.20]), (.36, CI[.30,.42]), respectively. Thus, the tests confirm the mediating effects of Message Quality on all source characteristics on WOM influence and hypotheses H6, H7, H8, and H9 are all supported.

\section{- INSERT TABLE 3 ABOUT HERE -}

\section{Discussion}

Message and source are two primary elements which exist in communications. This study sought to examine if the receiver's evaluation of WOM sources will affect the judgement of 
message content and, in turn, WOM influence. The results of this study confirm this relationship, demonstrating the mediating role of message quality on the relationship between the four source characteristics under study and WOM influence. In summary, the findings suggest that the use of relevant source characteristics in delivering a WOM message will increase WOM influence.

Of the four source characteristics examined, the findings show the significant, positive influence of opinion leadership and expertise on message quality, with opinion leadership having the strongest impact. This result confirms the significant role of opinion leadership in WOM communication (Gilly et al., 1998). The greater effect of opinion leadership over expertise is consistent with Martin and Lueg (2013), indicating the importance of source experience rather than source expertise. That is, WOM receivers tend to prefer information from people who are familiar with, and experienced in, the purchase context. In the higher education context, prospective students would listen to the career advisors, teachers or people in their network who they usually ask information regarding universities rather than experts or professors. Prospective students may ask these people because they are familiar with the context as a consumer. Experts or professors are familiar with the context too, just not as consumers.

The results are also consistent with previous studies which identified the important role of trustworthiness in WOM sources (Martin and Lueg, 2013; Reichelt et al., 2014). In the digital era, the trustworthiness of online sources could be very important for information receivers because they cannot evaluate the expertise of the online communicators. For example, Brown et al. (2007) argued that website reputation is more important than the expertise of the contributors. Within the credence services such as higher education, this trustworthiness may be essential because consumers do not have prior personal knowledge regarding considered attributes.

Of the four hypotheses related to the examined characteristics, the hypothesis regarding the impact of homophily is the only one not supported and has the weakest positive effect. In this study, homophily is found to have a positive direct effect on message quality and positive indirect effect on WOM influence, though the weakest. This result can be explained by Reichelt's et al. (2014) finding that the use of similar of sources satisfies the social function of consumers but has no utilitarian function. In a service context where consumers need to 
find information regarding credence attributes, their information acquisition activities are more likely to be associated with the utilitarian function rather than social function. However, because of the data collection context of higher education, the closest similar WOM sources are likely to be family friends. These sources may not have sufficient experience in the considered attributes (e.g. course content, teaching staff qualification) because they did not attend a university recently or at all, and thus homophily in this context primarily satisfies the social function.

The findings also illustrate the moderating effects of the involvement in the purchase context and the valence of message content. High involvement was shown to strengthen the positive relationship between massage quality and WOM influence. This moderating effect is consistent with ELM theory which contends that argument quality has a greater impact on attitude under high involvement (Petty et al., 1983). In term of valence, when receiving positive information, the message content will have a greater impact on WOM influence. This result shows that consumers are more confident to elaborate and adopt a WOM message when it delivers positive content. As empirical support for moderating relationships are very difficult to obtain, even at $\mathrm{p}<0.1$ (Podsakoff et al., 1995), empirical support for moderating relationships is important for theory testing.

\section{Implications for theory and practice}

From our knowledge, this is the first empirical study to seek a deeper understanding of the relationship between source characteristics and message quality. The study differentiates the power of each source characteristic on the judgement of message quality, which is helpful for marketing practice in selecting the source for WOM marketing strategies.

Previous research has indicated that WOM sources influence the effectiveness of WOM delivered to receivers, though the influence varies depending on source characteristics, namely expertise, trustworthiness, source homophily and opinion leadership. However, the effects of these characteristics via the mediating variable of message quality have not been previously considered. The findings of this study confirm the mediating role of message quality. This mediation explains the process that underlies the known relationships between source characteristics and WOM influence. It also contributes to the understanding of the link between the two processing routes of ELM theory. Although the peripheral process occurs when elaboration likelihood is low, the evaluation of peripheral cues or source characteristics 
does not lead directly to the attitude change. It plays a stimulating role for the central process, which leads to message evaluation and attitude change. Regarding information processing theories, the findings support the view that central and peripheral processes of ELM do not exist separately, but influence each other. This is different from other WOM research where the ELM treats such information processing as isolated routes.

This study has several implications for practitioners, marketers, and managers. Although WOM is non-commercial communications and are not generated from practitioners, it can be stimulated through marketing campaigns (Godes and Mayzlin, 2009; López and Sicilia, 2013). From a practical perspective, the findings of this study support two primary ways to enhance WOM in marketing strategies. First, marketers can develop referral programs to encourage consumers to recommend their products or services to other consumers; second, marketers can employ seeding programs to encourage influencers to generate information, share commercially generated messages or co-create with the brand/organisation those messages and then share them on their own channels (López and Sicilia, 2013).

Thus, with the nature of information processing in the WOM context more deeply understood, practitioners can consider how the message and sources are evaluated by consumers and alter messages accordingly. To develop a WOM marketing strategy, for example a seeding program, practitioners need to identify the most effective influencers for the program and the most appropriate WOM message aimed to the potential consumers. According to the findings, opinion leaders, or trustworthy people, should be the targeted sources or seeds of information. Identifying who they are and reaching these potential sources are fundamental to the success of the WOM marketing campaign. Furthermore, understanding that the source characteristics will have an indirect effect on WOM influence through the mediation of message quality, marketers and managers should also carefully design relevant messages to improve the effectiveness of WOM marketing. For each source characteristic, the messages should be customised to match with the voice of source. Organisations can also educate influencers on how to best design messages to enhance message quality and capitalise on the source characteristics they represent to consumers.

\section{Limitations and future research}

Limitations of this research are noted and provide avenues for future research. Data collection was conducted in the higher education context, a credence service where attributes may be 
difficult to evaluate for prospective consumers, limiting generalisability. . Further research should be conducted in other sectors to analyse the impact of source characteristics in different purchase contexts.

The need to extend this research across purchase contexts is especially relevant to the construct of homophily. As discussed, the effect of homophily is inconsistent across previous studies. Brown and Reingen (1987) predicted but did not confirm the impact of homophily, while Gilly et al. (1998) indicated that the effects of homophily can be inverted and vary depending on the demographic or perceptual form of homophily, as well as the types of products. Finally, Chu and Kim (2011) found that homophily is negatively related to WOM opinion seeking. These conflicting results indicate that homophily is a complex factor which varies from demographic homophily, lifestyle or attitude homophily (Brown and Reingen, 1987), and across different contexts (Gilly et al., 1998). Thus, further examination of the nuances of homophily in WOM research is needed and provides a rich area for future research.

The role of demographics and offline-online platforms were not the focus of this study. Future research can extend the investigation to examine source-message relationships in various platforms to compare the difference between information processing in traditional WOM and eWOM. Moreover, a more diversified sample of respondents can provide further findings and improve applicability to multiple groups of consumers.

An extended investigation on involvement and valence could be an interesting avenue for future research. This study only focuses on the task involvement, which is related to the importance and motivation to concentrate on the decision-making process. Involvement is driven by multiple factors and different forms of involvement potentially have different effects on information processing (e.g. enduring involvement in the decision-making process or the situational involvement with communication). Moreover, due to the diversification of communication platforms, valence should be further examined under different forms (e.g., comment valance, review valence or rating valence). The development of a multi-item scale for valence should be pursued to better reflect this construct. 


\section{References}

Allsop, D.T., Bassett, B.R. and Hoskins, J.A. (2007), "Word-of-Mouth Research: Principles and Applications", Journal of Advertising Research, Vol. 47, No. 4, pp. 398-411.

Baker, A.M., Donthu, N. and Kumar, V. (2016), "Investigating How Word-of-Mouth Conversations About Brands Influence Purchase and Retransmission Intentions", Journal of Marketing Research, Vol. 53, No. 2, pp. 225-39.

Ballantine, P.W. and Yeung, C.A. (2015), "The effects of review valence in organic versus sponsored blog sites on perceived credibility, brand attitude, and behavioural intentions", Marketing Intelligence \& Planning, Vol. 33, No. 4, pp. 508-21.

Bansal, H.S. and Voyer, P.A. (2000), "Word-of-Mouth Processes within a Services Purchase Decision Context", Journal of Service Research, Vol. 3, No. 2, pp. 166-77.

Berger, J. (2014), "Word of mouth and interpersonal communication: A review and directions for future research", Journal of Consumer Psychology, Vol. 24, No. 4, pp. 586-607.

Bordia, P., DiFonzo, N., Haines, R. and Chaseling, E. (2005), "Rumors Denials as Persuasive Messages: Effects of Personal Relevance, Source, and Message Characteristics", Journal of Applied Social Psychology, Vol. 35, No. 6, pp. 1301-31.

Brown, J., Broderick, A.J. and Lee, N. (2007), "Word of mouth communication within online communities: Conceptualizing the online social network", Journal of Interactive Marketing, Vol. 21, No. 3, pp. 2-20.

Brown, J.J. and Reingen, P.H. (1987), "Social Ties and Word-of-Mouth Referral Behavior", Journal of Consumer Research, Vol. 14, No. 3, pp. 350-62.

Cacioppo, J.T. and Petty, R.E. (1984), "The elaboration likelihood model of persuasion", in Kinnear, T.C. (ed.), NA - Advances in Consumer Research, Association for Consumer Research, Provo, UT, vol. 11, pp. 673-5.

Cheung, C.M.K. and Thadani, D.R. (2012), "The impact of electronic word-of-mouth communication: A literature analysis and integrative model", Decision Support Systems, Vol. 54, No. 1, pp. 461-70.

Cheung, M.Y., Luo, C., Sia, C.L. and Chen, H. (2009), "Credibility of electronic word-ofmouth: informational and normative determinants of on-line consumer recommendations", International Journal of Electronic Commerce, Vol. 13, No. 4, pp. 9-38.

Childers, T.L. (1986), "Assessment of the Psychometric Properties of an Opinion Leadership Scale", Journal of Marketing Research, Vol. 23, No. 2, pp. 184-8.

Chu, S.-C. and Kim, Y. (2011), "Determinants of consumer engagement in electronic wordof-mouth (eWOM) in social networking sites", International Journal of Advertising, Vol. 30, No. 1, pp. 47-75.

East, R., Hammond, K. and Lomax, W. (2008), "Measuring the impact of positive and negative word of mouth on brand purchase probability", International Journal of Research in Marketing, Vol. 25, No. 3, pp. 215-24.

Fornell, C. and Larcker, D.F. (1981), "Evaluating Structural Equation Models with Unobservable Variables and Measurement Error", Journal of Marketing Research, Vol. 18, No. 1, pp. 39-50. 
Gilly, M.C., Graham, J.L., Wolfinbarger, M.F. and Yale, L.J. (1998), "A Dyadic Study of Interpersonal Information Search", Journal of the Academy of Marketing Science, Vol. 26, No. 2, pp. 83-100.

Godes, D. and Mayzlin, D. (2009), "Firm-created word-of-mouth communication: Evidence from a field test", Marketing Science, Vol. 28, No. 4, pp. 721-39.

Hair, J.F., Black, W.C., Babin, B.J., Anderson, R.E. and Tatham, R.L. (2006), Multivariate data analysis, 6th edn, Pearson Prentice Hall Upper Saddle River, NJ.

Hayes, A.F. (2013), Introduction to mediation, moderation, and conditional process analysis: A regression-based approach, Guilford Press.

Hennig-Thurau, T., Gwinner, K.P., Walsh, G. and Gremler, D.D. (2004), "Electronic wordof-mouth via consumer-opinion platforms: What motivates consumers to articulate themselves on the Internet?", Journal of Interactive Marketing, Vol. 18, No. 1, pp. 3852.

Hovland, C.I. and Weiss, W. (1951), "The Influence of Source Credibility on Communication Effectiveness", Public Opinion Quarterly, Vol. 15, No. 4, pp. 635-50.

Jalilvand, M.R., Salimipour, S., Elyasi, M. and Mohammadi, M. (2017), "Factors influencing word of mouth behaviour in the restaurant industry", Marketing Intelligence \& Planning, Vol. 35, No. 1, pp. 81-110.

Kang, Y.S. and Herr, P.M. (2006), "Beauty and the Beholder: Toward an Integrative Model of Communication Source Effects", Journal of Consumer Research, Vol. 33, No. 1, pp. 123-30.

López, M. and Sicilia, M. (2013), "How WOM marketing contributes to new product adoption: Testing competitive communication strategies", European Journal of Marketing, Vol. 47, No. 7, pp. 1089-114.

MacKenzie, S.B., Podsakoff, P.M. and Podsakoff, N.P. (2011), "Construct Measurement and Validation Procedures in MIS and Behavioral Research: Integrating New and Existing Techniques", MIS Quarterly, Vol. 35, No. 2, pp. 293-334.

Mahapatra, S. and Mishra, A. (2017), "Acceptance and forwarding of electronic word of mouth", Marketing Intelligence \& Planning, Vol. 35, No. 5, pp. 594-610.

Martin, W.C. and Lueg, J.E. (2013), "Modeling word-of-mouth usage", Journal of Business Research, Vol. 66, No. 7, pp. 801-8.

Mazzarol, T., Sweeney, J.C. and Soutar, G.N. (2007), "Conceptualizing word-of-mouth activity, triggers and conditions: an exploratory study", European Journal of Marketing, Vol. 41, No. 11/12, pp. 1475-94.

Ohanian, R. (1990), "Construction and Validation of a Scale to Measure Celebrity Endorsers' Perceived Expertise, Trustworthiness, and Attractiveness", Journal of Advertising, Vol. 19, No. 3, pp. 39-52.

Park, C. and Lee, T.M. (2009), "Information direction, website reputation and eWOM effect: A moderating role of product type", Journal of Business Research, Vol. 62, No. 1, pp. $61-7$.

Patti, C.H. and Chen, C.H. (2009), "Types of Word-of-Mouth Messages: Information Search and Credence-Based Services", Journal of Promotion Management, Vol. 15, No. 3, pp. 357-81. 
Petty, R.E. and Cacioppo, J.T. (1986), "The elaboration likelihood model of persuasion", Advances in experimental social psychology, Vol. 19, pp. 123-205.

Petty, R.E., Cacioppo, J.T. and Schumann, D. (1983), "Central and Peripheral Routes to Advertising Effectiveness: The Moderating Role of Involvement", Journal of Consumer Research, Vol. 10, No. 2, pp. 135-46.

Podsakoff, P.M., MacKenzie, S.B., Ahearne, M. and Bommer, W.H. (1995), "Searching for a needle in a haystack: Trying to identify the illusive moderators of leadership behaviors", Journal of Management, Vol. 21, No. 3, pp. 423-70.

Pornpitakpan, C. (2004), "The Persuasiveness of Source Credibility: A Critical Review of Five Decades' Evidence", Journal of Applied Social Psychology, Vol. 34, No. 2, pp. 243-81.

Preacher, K.J. and Hayes, A.F. (2008), "Asymptotic and resampling strategies for assessing and comparing indirect effects in multiple mediator models", Behavior Research Methods, Vol. 40, No. 3, pp. 879-91.

Reichelt, J., Sievert, J. and Jacob, F. (2014), "How credibility affects eWOM reading: The influences of expertise, trustworthiness, and similarity on utilitarian and social functions", Journal of Marketing Communications, Vol. 20, No. 1-2, pp. 65-81.

Slater, M.D. and Rouner, D. (1996), "How Message Evaluation and Source Attributes May Influence Credibility Assessment and Belief Change", Journalism \& Mass Communication Quarterly, Vol. 73, No. 4, pp. 974-91.

Sweeney, J.C., Soutar, G.N. and Mazzarol, T. (2008), "Factors influencing word of mouth effectiveness: receiver perspectives", European Journal of Marketing, Vol. 42, No. 3/4, pp. 344-64.

---- (2012), "Word of mouth: measuring the power of individual messages", European Journal of Marketing, Vol. 46, No. 1/2, pp. 237-57.

---- (2014), "Factors enhancing word-of-mouth influence: positive and negative servicerelated messages", European Journal of Marketing, Vol. 48, No. 1/2, pp. 336-59.

Voyer, P.A. and Ranaweera, C. (2015), "The impact of word of mouth on service purchase decisions: Examining risk and the interaction of tie strength and involvement", Journal of Service Theory and Practice, Vol. 25, No. 5, pp. 636-56.

Wangenheim, F.V. and Bayón, T. (2004), "The effect of word of mouth on services switching", European Journal of Marketing, Vol. 38, No. 9/10, pp. 1173-85.

Westbrook, R.A. (1987), "Product/Consumption-Based Affective Responses and Postpurchase Processes", Journal of Marketing Research, Vol. 24, No. 3, pp. 258-70.

Zaichkowsky, J.L. (1985), "Measuring the Involvement Construct", Journal of Consumer Research, Vol. 12, No. 3, pp. 341-52. 
Figure 1: Conceptual model

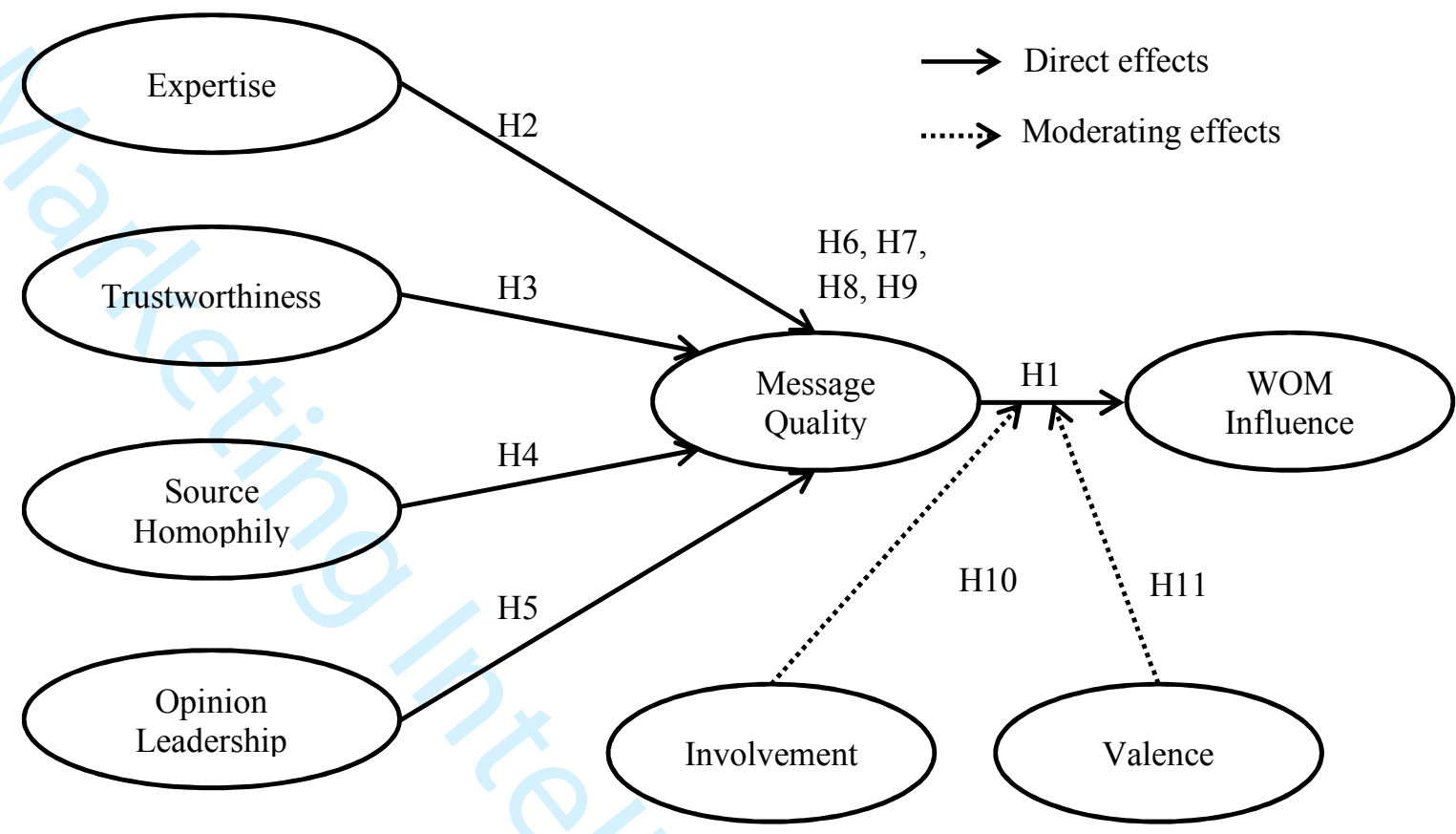

Table 1: Results of the measurement model assessment

\begin{tabular}{lr}
\hline Measures & $\begin{array}{r}\text { Factor } \\
\text { loading }\end{array}$ \\
\hline
\end{tabular}

Expertise $(\mathrm{AVE}=.63 ; \alpha=.90 ; \mathrm{CR}=.90)$

This person is an expert

This person is experienced

This person is knowledgeable

This person is qualified

This person is skilled

Trustworthiness $(\mathrm{AVE}=.74 ; \alpha=.92 ; \mathrm{CR}=.92)$

This person is honest

This person is reliable

This person is sincere

This person is trustworthy

Homophily $(\mathrm{AVE}=.74 ; \alpha=.91 ; \mathrm{CR}=.92)$

I usually spend free time with this person

We have a similar outlook on life

We share common interests

We have similar likes and dislikes

Opinion leadership (AVE $=.54 ; \alpha=.76 ; C R=.78)$

This person provided me with a great deal of information about universities

information from them than I provide in return

In general, I often use this person as a source of advice

Message Quality $(\mathrm{AVE}=.56 ; \alpha=.92 ; \mathrm{CR}=.91)$ 
The message was informative

The message was reliable

The message was clear

The message was specific

The message was elaborate

The message was explicit

The message was intense

The message was reinforcing

WOM Influence $(\mathrm{AVE}=.54 ; \alpha=.77 ; \mathrm{CR}=.78)$

This conversation has a significant influence on my university choice decision

This conversation mentioned helpful things I had not considered

This conversation really helped me make the decision about selecting a

Model Fit indices: Chi-square $=770.639, d f=302, p=.000$, Chi-square $/ d f=2.552$, Root

Mean Square Error of Approximation (RMSEA) $=0.055$, Tucker Lewis Index (TLI) $=0.941$, Normed Fit Index (NFI) $=0.919$ and Comparative Fit Index $(C F I)=0.949$

$N=509 ; \alpha=$ Cronbach's alpha; $C R=$ Composite reliability; $A V E=$ Average variance extracted.

Table 2: Results of structural model

\begin{tabular}{llll}
\hline & $\begin{array}{l}\text { Standardised } \\
\text { Estimate }\end{array}$ & p-value & Hypotheses \\
\hline Message Quality $\rightarrow$ WOM Influence & $.67^{* *}$ & .00 & H1: Supported \\
Source Expertise $\rightarrow$ Message Quality & $.19^{* *}$ & .00 & H2: Supported \\
Trustworthiness $\rightarrow$ Message Quality & $.31^{* *}$ & .00 & H3: Supported \\
Homophily $\rightarrow$ Message Quality & $.07^{*}$ & .03 & H4: Not supported \\
Opinion Leadership $\rightarrow$ Message Quality & $.44^{* *}$ & .00 & H5: Supported \\
MQuality*Involvement $\rightarrow$ WOM Influence & $.09^{* *}$ & .01 & H10: Supported \\
MQuality*Valence $\rightarrow$ WOM Influence & $.07^{*}$ & .04 & H11: Supported \\
\hline R squared values: Message Quality: $0.66 ;$ WOM Influence: 0.45 & \\
\hline$N=509 ; * * p<0.01, * p<0.05$ & & \\
\hline
\end{tabular}

Table 3: Bootstrap test of indirect effects

\begin{tabular}{|c|c|c|c|c|c|}
\hline Indirect Effects & Effect & SE & $\begin{array}{l}\text { Boot } \\
\text { LLCI }\end{array}$ & $\begin{array}{l}\text { Boot } \\
\text { ULCI }\end{array}$ & Hypotheses \\
\hline $\begin{array}{l}\text { Expertise } \rightarrow \text { Message Quality } \rightarrow \\
\text { WOM Influence }\end{array}$ & .32 & .03 & .26 & .38 & H6: Supported \\
\hline $\begin{array}{l}\text { Trustworthiness } \rightarrow \text { Message Quality } \\
\rightarrow \text { WOM Influence }\end{array}$ & .36 & .03 & .30 & .42 & H7: Supported \\
\hline $\begin{array}{l}\text { Homophily } \rightarrow \text { Message Quality } \rightarrow \\
\text { WOM Influence }\end{array}$ & .15 & .02 & .11 & .20 & H8: Supported \\
\hline $\begin{array}{l}\text { Opinion Leadership } \rightarrow \text { Message } \\
\text { Quality } \rightarrow \text { WOM Influence }\end{array}$ & .36 & .03 & .30 & .42 & H9: Supported \\
\hline
\end{tabular}


Figure 2: The moderating effect of Involvement

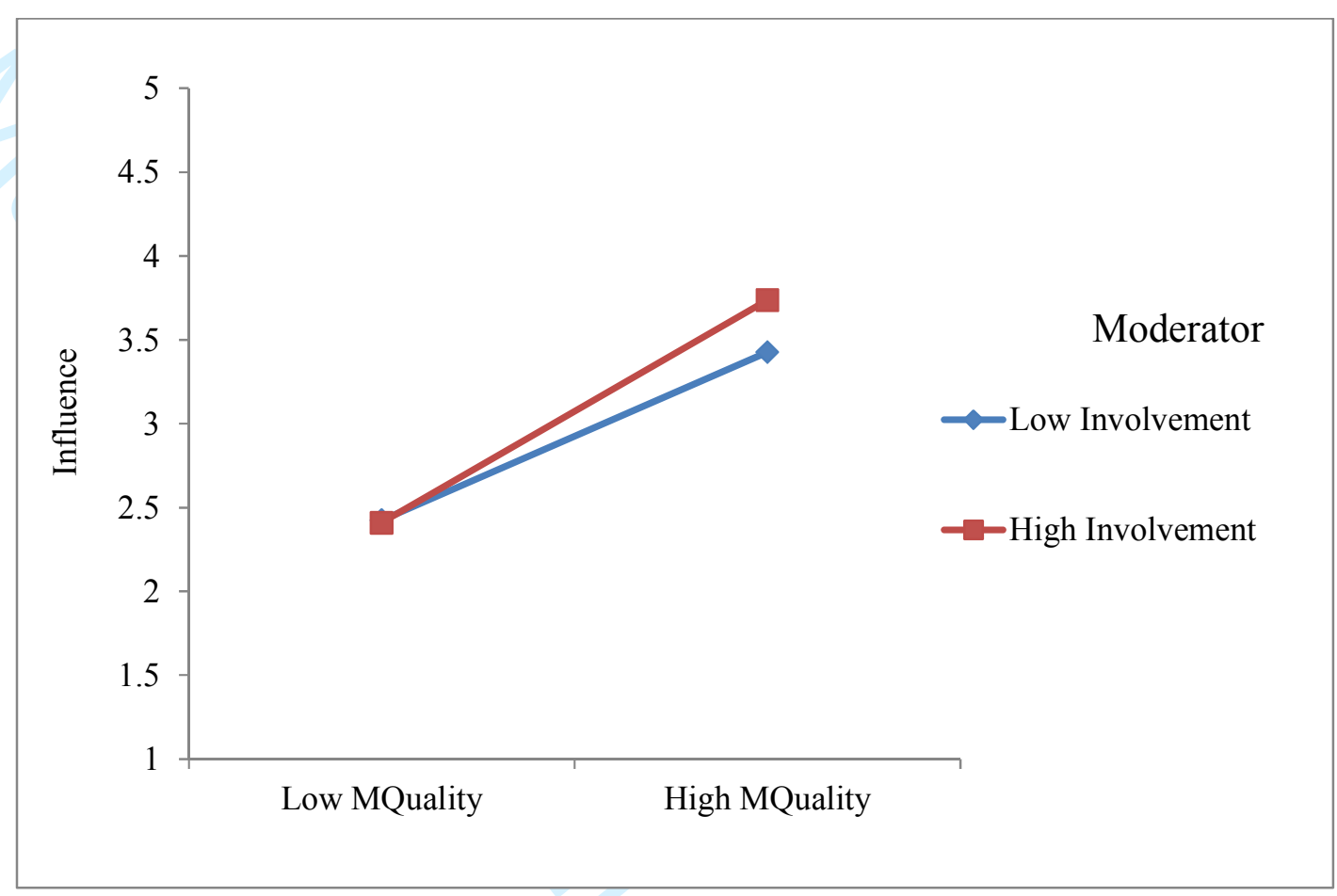

Figure 3: The moderating effect of Valence

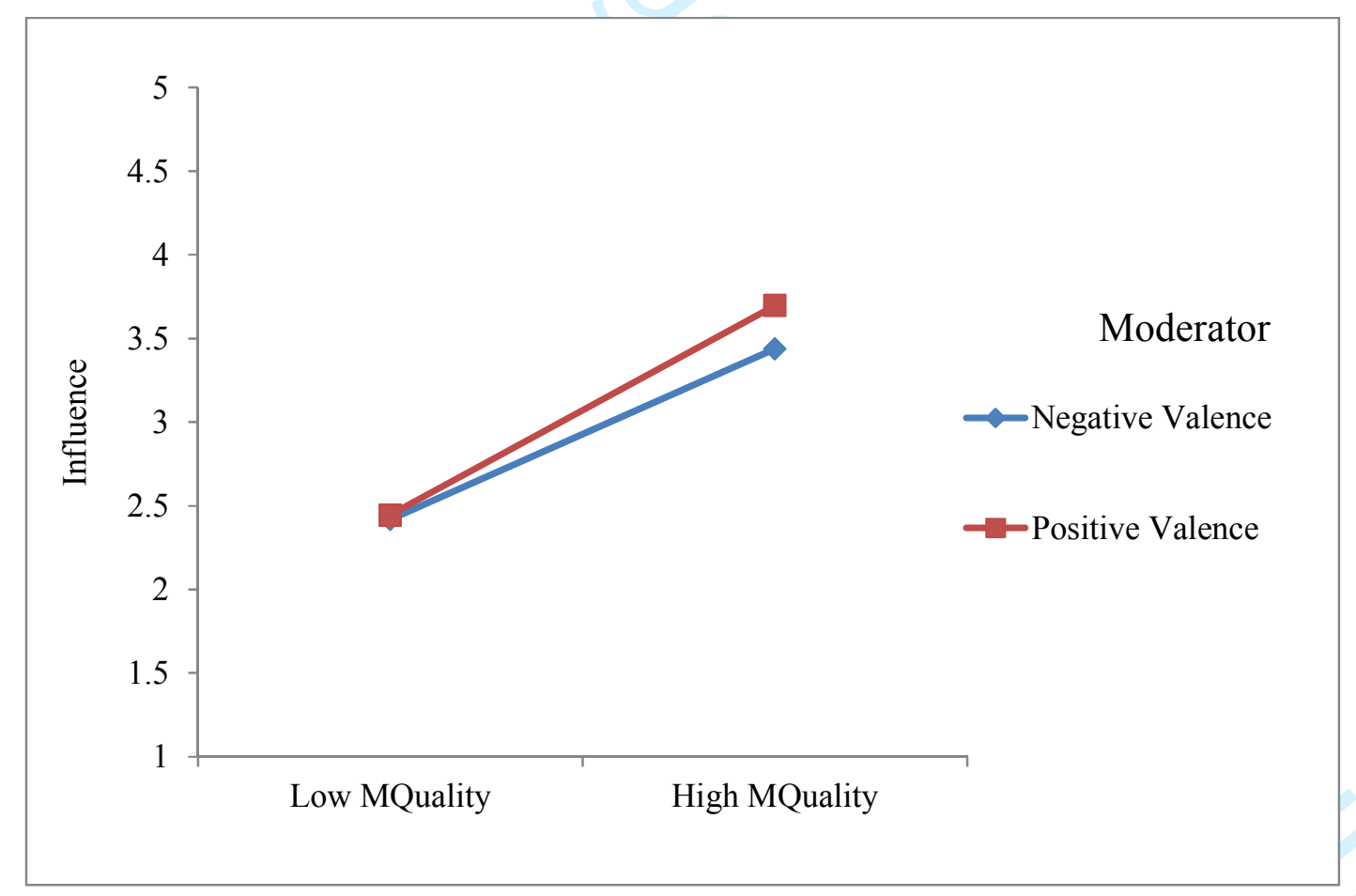

